\title{
Reflexões sobre O caso de Ellen West. Estudo antropológico-clínico, de Binswanger
}

Manoel Tosta Berlinck

Ana Cecília Magtaz

$O$ relato do caso de Ellen West ilustra de forma magistral que a questão da anorexia não está somente ligada a um problema alimentar. Revela tratar-se de um conflito entre o ego e o superego e, portanto, representa uma neurose narcísica. A severidade do superego baseia-se nas regras de cumprimento dos ideais. Quanto mais esses forem elevados, menos poderão ser satisfeitos. Geralmente, para ser objeto de investimento amoroso do superego o ego tem que se mostrar como o que não é: o ideal.

Palavras-chave: Anorexia, melancolia, neurose narcísica 
Em 1944, o psiquiatra suíço Ludwig Binswanger (1881-1966) publicou O caso de Ellen West. Estudo antropológico-clínico. Descreve, de forma detalhada e cuidadosa, aspectos de sua herança, de sua biografia, do curso da enfermidade e de sua trágica morte. A leitura desse admirável e valioso texto possibilita uma reflexão clínico-teórica a respeito dos distúrbios da oralidade como sintomas da melancolia.

Binswanger chama a atenção para o fato de Ellen saber muito pouco sobre os dez primeiros anos de sua vida. Segundo ela e seus pais, fora uma menina muito vivaz, porém violenta e teimosa. Desafiadora e desobediente, enfrentava as ordens paternas e dificilmente mudava de opinião. Queria ser ela mesma, sempre.

Há um fato marcante para os pais que chama a atenção de Binswanger. Eles mostram a Ellen um ninho de passarinho numa árvore. Ela diz que não é um ninho. Não existe um ninho onde todos o vêem. Todos ficam intimidados com o tom de verdade e teimosia da menina. Manifesta-se, assim, uma recusa da percepção específica pela via da negatividade.

Quando criança lembra de ter sido afetada por intensos sentimentos de vazio e opressão. Ótima aluna, rígida com os estudos, exigente com as notas, amava ler e escrevia suas poesias em um diário. Chupou o dedo polegar até completar 16 anos, e até essa idade só gostava das brincadeiras de meninos. Aos 17 anos, escreveu uma poesia, revelando seu desejo de ser menino porque poderia ser soldado, não temer nenhum inimigo e morrer segurando uma espada. Poesias desse período já revelavam uma variação de humor. Ellen lia muito e se preocupava intensamente com os problemas sociais, sentindo profundamente o contraste entre sua posição social abastada e a "das massas", inferiorizada.

Traça alguns planos para melhorar as condições das massas. Trata-se de um grande ideal a ser alcançado, e pelo qual decide dedicar sua vida e seu trabalho.

Aos 18 anos dispõe de um diário no qual discorre longamente sobre o trabalhar. Ela diz: "O trabalho é o ópio contra o sofrimento e a dor (...) Quando as colunas do mundo trepidam, quando se extingue a luz de nossa felicidade e se esfuma o prazer de viver, só uma coisa nos salva da loucura: o trabalho" (p. 291).

Nesse momento, Ellen oscila entre a grandeza do ideal e a pequenez humana. "Antigos planos e ilusões, que nunca chegaram a realizar-se, a ilimi- 
tada esterilidade do mundo e a nossa infinita pequenez se entrelaçam ante a nossa alma cansada" (p. 291-292). Os elementos antagônicos são: o ar e a terra; a elevação e a queda. A existência de Ellen se move em um espaço psíquico marcado pelo funcionamento vertical, entre o sucesso e o fracasso do ideal. ${ }^{1}$

Nessa mesma época, aos 18 anos, Ellen vive o desejo de ser delicada e etérea como as amigas que seleciona e idealiza. Suas poesias, de um lado, exaltam a luz e o amor; de outro, a sombra e o fúnebre. Aos 19 anos começa a montar a cavalo e, como tudo o que faz, pratica a montaria com excessiva intensidade, como se essa fosse a única tarefa e a razão de sua vida. Trata-se de uma fidelidade ao objeto ideal. Aos vinte anos sente-se feliz e cheia de esperanças. Suas poesias irradiam o gozo esplendoroso da vida. Ama a vida apaixonadamente; o mundo the pertence porque tem o sol, o vento, a beleza, tudo para si. Seu Deus é o Deus da vida e do gozo, da força e da esperança; consome-lhe uma sede ardente de saber tudo, querer descobrir o segredo do universo.

Nesse período apaixona-se e, a pedido do pai, rompe o namoro. Estava numa viagem à Sicília e essa foi a última vez que pôde comer tranqüila. Começa a escrever em seu diário as sombras da dúvida e do medo. Sente-se pequena e totalmente abandonada em um mundo que não pode entender - nada entender.

Aí algo novo se apresenta; um medo concreto, o medo de engordar. Sua estada na Sićlia desperta nela um apetite voraz e acaba engordando bastante. Nessa época, Ellen começa a fazer longas caminhadas para perder peso.

Aos 21 anos, seu estado mental é claramente depressivo. A idéia fixa de estar gorda a atormenta, levando-a a intensificar as caminhadas, tornando-se uma errante. Seus pés chegam a ficar feridos, porém não se queixa de dor. ${ }^{2}$

Muito importante sobre a errância de Ellen: ela não encontra lugar em nenhuma parte. Não tem paz, não consegue sentar e parar, que dirá relaxar. Sentese inútil e indigna e com medo de tudo: do sol e da escuridão, do silêncio e do ruído. Não há um ninho para descansar. Este ninho não existe, não é visto por Ellen desde a sua infância.

Sente-se, a cada dia que passa, "mais gorda, mais velha e mais feia" (p. 294). Quer, então, buscar a morte. Entretanto, aos poucos, vai se recuperando de sua tristeza. Continua dizendo que quer fazer algo grande e alcançar seu magnífico ideal. A boa vida de judia burguesa é por ela odiada.

1. Ver o capítulo sobre Simone Weil no livro de Raimbault, G. e Eliacheff, C. Lês indomptables. Figures de l'anorexie, 2001, p. 156-229. Simone Weil desde a infância apresentou-se como uma menina caprichosa e indomável. Na mesma época, e assim como Ellen, era muito inteligente e movida por um grande ideal a ser alcançado.

2. Ver o caso Lígia abordado em Fernandes, M.H., Transtornos alimentares. Anorexia e bulimia, p. 144. 
Aos 22 anos, novamente melancólica, passa a amar e odiar tudo com toda a intensidade de sua alma. Aos 23, vive um colapso em função de um desapontamento amoroso Tem uma aventura com seu professor de equitação e ele a desaponta. Continua estudando, mas não consegue mais ficar sozinha e nem liberar-se da idéia fixa de não poder engordar.

Agora, o medo de engordar vem acompanhado por um afã crescente por comer, especialmente doces, o que se torna irresistível quando se encontra cansada e nervosa por ter estado com outras pessoas. Na presença dos outros, não experimenta satisfação em comer; unicamente sente prazer quando come sozinha. (p. 298)

A cada separação e descontentamento, Ellen busca emagrecer mais. Assim encontrava a "chave do seu bem-estar" (p. 299), da mesma forma como foi visto anteriormente a respeito das pacientes de Charles Lasègue. A ganhar peso, passava horas chorando, sentindo-se uma fracassada.

Aos 26 anos casa-se com um primo e pensa que, então, conseguirá desfazer-se de sua idéia fixa, mas não é isso o que acontece. Nessa época, o conflito entre o desejo de comer impunemente e o medo de engordar se intensifica.

Aos 29 sofre um aborto espontâneo. Passa a ficar atormentada pelo desejo de ter um filho e, ao mesmo tempo, pelo medo de engordar. Cessa a menstruação, antes regular. Passa a ingerir, diariamente, laxantes e remédios para a tireóide. Continua trabalhando energicamente pelo bem-estar social e, aos trinta anos, tornase vegetariana e passa a provocar o vômito todas as noites.

Aos 32 anos ingere enormes quantidades de laxantes e se encontra cada vez mais fraca e torturada. Inicia um tratamento psicanalítico e passa a reconhecer seus pensamentos fixos e seu movimento contínuo, mas não quer renunciar ao seu ideal, isto é, não consegue livrar-se da posição de servir ao seu ideal.

Aos 33 tenta, por duas vezes, o suicídio. Vive um imenso terror depois de comer e diz: "Sinto medo de minha fome porque não consigo pensar, nem ver o mundo com clareza. (...) Estou num calabouço e não posso sair. (...) Tenho a impressão de ser um cadáver entre as pessoas" (p. 317).

Fica internada durante muitos meses e não apresenta melhora significativa, pois sempre estava se movimentando e isso impressionava a todos que dela tratavam. Quando sai da internação e volta para casa, toma uma dose mortal de veneno. Quando encontrada, seu semblante estava como nunca havia parecido em vida: tranqüilo, feliz e sereno.

Para Ellen, segundo Binswanger, todo o mundo constituía uma ameaça. O nada acaba sendo sua salvaguarda. Ela dizia que se não podia conservar-se jovem, então melhor nada. Com o desejo de se conservar magra, jovem e bonita, e o pavor de ficar gorda, sua corporeidade assume cada vez mais o papel principal no dramático jogo da existência consigo mesma. 
Tudo o que aborrece Ellen é aquilo que impede seu eu desafiante, violento; tudo o que limita, ameaça e contraria sua sensação de domínio. Ellen se impunha restrições existenciais, buscando ser um vazio existencial, uma tumba. Torna-se escrava, adicta, de um movimento contínuo, circular, uma errância sem destino de sua existência sem futuro.

Pode-se pensar na tristeza do mundo se reduzindo a uma tristeza corporal em Ellen. A noção de corpo em sofrimento, trabalhada pela psicanalista francesa Micheline Enriquez (1999), é fundamental e vai ao encontro da análise de Binswanger.

A partir de impressões clínicas, Enriquez observa vivências como se o corpo invadisse a totalidade do espaço analítico e psíquico, mas ao mesmo tempo parecesse não ter proprietário. É preciso dar-lhe vida e devolvê-lo a quem pertence. O paciente não consegue dizer "eu sofro", mas simplesmente "sinto frio, calor, enjôo, fome, dói aqui, dói ali, dói demais". E isto repetidamente. Não há lugar para o sonho, lembranças do passado e associações a partir de uma lembrança. Não há, portanto, a possibilidade de se entregar a alguma atividade representativa de prazer e desejos próprios. O que há é a manutenção do corpo em sofrimento, tentando reduzi-lo a um corpo de necessidade, sem demanda afetiva, protegido de todo efeito de fala. Assim, mantendo o corpo conservado em sofrimento, o sujeito tenta se proteger do abuso e do poder que o outro possa ter sobre ele.

É possível pensar que Ellen talvez precisasse, em primeiro lugar, voltar a habitar seu corpo para depois colocar em palavras seu sofrimento psíquico, sua imensa tristeza. Seu corpo em sofrimento revela uma sexualidade sem palavras, sem ternura e sem deleite. A ação maníaca, sua errância sem destino, parece ser uma defesa contra um vazio inapreensível que apequena o Eu numa sensação de inferioridade da qual não tem consciência.

Voltando a Binswanger, Ellen vive um confinamento mental e nutre somente seus pontos maus e seus vícios. Para ela, sua existência já estava madura para morrer. Envelheceu jovem, num envelhecimento existencial. É possível dizer que Ellen se consumiu, foi devorada pelo seu Ideal; viveu uma paixão bulímica de si para poder conservar-se e não se alterar mais (Ideal). A morte, então, configurou-se como uma partida para sempre para poder renascer e gerar um novo corpo. Chama a atenção que Ellen sempre quis ser ela mesma, mas o que buscou foi não ser ela mesma, e sim ser o ideal. Ser uma outra coisa travando uma luta contínua contra o destino, apresentando uma recusa do seu sexo, seu lugar social, suas tradições, sua paixão pelos doces, sua tendência a engordar e sua doença. A ação maníaca de Ellen é, dessa forma, um agir para não pensar, sem a possibilidade do cuidado de si, nem dizer "eu sou", "eu desejo".

O relato do caso de Ellen West ilustra de forma magistral que a questão da anorexia não está somente ligada a um problema alimentar. Revela tratar-se de um 
conflito entre o ego e o superego e, portanto, representa uma neurosa narcísica. A severidade do superego baseia-se nas regras de cumprimento dos ideais. Quanto mais esses forem elevados, menos poderão ser satisfeitos. Geralmente, para ser objeto de investimento amoroso do superego o ego tem que se mostrar como o que não é: o ideal.

\section{Referências}

Binswanger, L. El caso de Ellen West. Estúdio antropológico-clínico. In: May, R.; Angel, E.; Ellenberg, H.F. (eds.). Existencia. Madrid: Editorial Gredos, 1977. p. 288434.

EnRiquez, Michelline. Nas encruzilhadas do ódio. Paranóia, masoquismo, apatia. São Paulo: Escuta, 1999.

Fernandes, M.H. Transtornos alimentares: anorexia e bulimia. São Paulo: Casa do Psicólogo, 2006.

Raimbault, G. e Eliacheff, C. Lês indomptables. Figures de l'anorexie. Paris: Poches Odile Jacob, 2001.

Resumos

(Reflexiones sobre $O$ caso de Ellen West. Estudo Antropológico-clínico, de Binswanger)

El relato del caso Ellen West ilustra de forma magistral que la cuestión de la anorexia no está sólo ligada a un problema de alimentación. Revela tratarse de un conflicto entre el yo y el ideal del yo y por consiguiente, representa una neurosis narcisista. La severidad de superyo se asienta en reglas de cumplimiento de ideales. Cuando más estos sean elevados menos podrán ser satisfechos. Generalmente para ser objeto de investidura amorosa del superyo el yo tiene que mostrarse como lo que no es: el ideal.

Palavrasclave: Anorexia, melancolía, manía, neurosis narcisista

(Réflexions sur Le cas Ellen West. Étude anthropologique-clinique, de Binswanger)

Le rapport du cas Ellen West illustre de façon magistrale que le problème de l'anorexie n'est pas uniquement lié à un problème d'alimentation. Il révèle qu'il s'agit d'un conflit entre le Moi et le Surmoi et que, par conséquent, il représente une névrose narcissique. La sévérité du Surmoi est basée sur les règles d'accomplissement des 
idéaux. Plus ceux-ci sont élevés, moins ils peuvent être atteints. En général, pour être l'objet d'investissement amoureux du Surmoi, le Moi est forcé de se montrer comme quelque chose qu'il n'est pas: l'idéal.

Mots clés: Anorexie, mélancolie, névrose narcissique

\section{Binswanger)}

(Reflections on the Case of Ellen West. An anthropological-clinical approach, by

The "Case of Ellen West" is an excellent illustration of why anorexia is not merely a food problem. It reveals a conflict between the ego and the superego, therefore representing a narcissistic neurosis. The severity of the superego is based on the rules for fulfilling ideals. The higher the ideals, the less they can be satisfied. For the ego to be the object of loving investment by the superego, the ego must try to be seen as what it is not, namely, the ideal.

Key words: Anorexia, melancholia, narcissistic neurosis

\section{Ana Cecília Magtaz}

Psicóloga; psicanalista; doutora pelo Programa de Estudos Pós-Graduados em Psicologia Clínica da Pontifícia Universidade Católica de São Paulo - PUC-SP (São Paulo, Brasil); professora do Curso de Psicopatologia da Faculdade de Saúde Pública da Universidade de São Paulo - USP (São Paulo, Brasil); assistente administrativa da Associação Universitária de Pesquisa em Psicopatologia Fundamental (São Paulo, SP, Brasil).

Rua Prof. Pedro da Cunha, 65/cj.31

05010-020 São Paulo, SP, Brasil

Tel.: 55113675.0584

e-mail: acmscaz@uol.com.br

\section{Manoel Tosta Berlinck}

Sociólogo; psicanalista; Ph.D. pela Cornell University; professor aposentado da Universidade Estadual de Campinas - Unicamp (Campinas, SP, Brasil); professor do Programa de Estudos Pós-Graduados em Psicologia Clínica da Pontifícia Universidade Católica de São Paulo - PUC-SP (São Paulo, Brasil), onde dirige o Laboratório de Psicopatologia Fundamental; presidente da Associação Universitária de Pesquisa em Psicopatologia Fundamental (2002-2004 e 2006-2008, São Paulo, SP, Brasil); editor responsável de Pulsional Revista de Psicanálise e da Revista Latinoamericana de Psicopatologia Fundamental; diretor da Livraria Pulsional - Centro de Psicanálise e da Editora Escuta (São Paulo, SP, Brasil).

Endereço: Rua Tupi, 397 - $10^{\circ}$ andar - sala 103

01233-001 São Paulo, SP, Brasil

Telefax: 55113825.8573

e-mail: mtberlin@uol.com.br 